\title{
Distorted Waveform Balancing Using an Artificial Bee Colony (ABC) Based Optimal Control for Mitigating Total Harmonics in Single Phase Inverter
}

\author{
N. M. Spencer Prathap Singh1, Kesavan Nair ${ }^{1}$, T. Ajith Bosco Raj2* \\ ${ }^{1}$ Department of EEE, CSI Institute of Technology, Thovalai, Tamilnadu, India \\ ${ }^{2}$ Department of ECE, PSN College of Engineering and Technology, Tirunelveli, Tamilnadu, India \\ Email: *ajithboscoraj@gmail.com
}

Received 6 April 2016; accepted 1 May 2016; published 12 July 2016

Copyright (C) 2016 by authors and Scientific Research Publishing Inc.

This work is licensed under the Creative Commons Attribution International License (CC BY). http://creativecommons.org/licenses/by/4.0/

(c) (i) Open Access

\begin{abstract}
The main objective of this paper is to reduce the total harmonics in a single phase voltage source inverter using Artificial Bee Colony (ABC) optimization technique for critical load applications. Single phase inverter is a non-linear load using power electronic components causing distortions in the load voltage and current wave patterns from the sinusoidal waveforms due to harmonics. The mapping state space model for a full bridge voltage source inverter was developed using output load resistance. An optimal ABC technique has been designed and optimized values are estimated using a full bridge voltage controlled inverter using Proportional Integral Algorithm. The MATLAB/SIMULINK tool and Experimental setup were implemented and their THD values were estimated. Also this ABC scheme is compared with the previous results such as PI Algorithm, Fuzzy logic controller and Neuro-fuzzy controllers. From the simulation and experimental results using $\mathrm{ABC}$ algorithm, it is observed that the total harmonics are mitigated considerably compared to previous results with respect to the power quality standards such as IEEE-519 and IEC 61000.
\end{abstract}

\section{Keywords}

Voltage Source Inverter, THD, Proportional Integral Controller, Artificial Bee Colony, Voltage Harmonics, Current Harmonics

\section{Introduction}

Inverter is a power electronics setup used to generate AC voltage from a DC source of desired magnitude and "Corresponding author.

How to cite this paper: Spencer Prathap Singh, N.M., Nair, K. and Ajith Bosco Raj, T. (2016) Distorted Waveform Balancing Using an Artificial Bee Colony (ABC) Based Optimal Control for Mitigating Total Harmonics in Single Phase Inverter. Circuits and Systems, 7, 2154-2167. http://dx.doi.org/10.4236/cs.2016.79187 
frequency. Single phase inverters are widely used in case of power failures to deliver power to critical loads, variable speed ac drives, induction heating, uninterruptible power supplies (UPS) for hospitals, security complexes, standby aircraft power supplies, traction, HVDC transmission lines and renewable energy applications which require pure sinusoidal waveform at the specified magnitude, frequency and low total harmonic distortion (THD). Normally, DC-AC inverters operate in pulse width modulation (PWM). During the process of inversion in a thyristorised power converter; harmonics of power frequency are produced on the converter. Reducing the harmonic content of the output voltage, current is one of the important tasks of the designers. Harmonics appear as undesirable noise. Poor power factor, Excessive temperature rise may weaken the reliability and life of the motors or equipment, sensitive electronic equipment malfunction, and increase the apparent power and oversizing of sources, acoustical noise in AC motor drives, etc. Hence an active harmonic reduction strategy is often desirable. Conventionally three harmonic reduction strategies such as switch control, vector control, and modulation technique are generally employed for harmonic reduction.

The inverters used for critical loads generally require less than $5 \%$ total harmonic distortion (THD) and the amplitude of individual harmonics should be less than $3 \%$ of the fundamental amplitude. The low THD value improves the dynamic response of the UPS in load variations. Single phase inverters are widely used due to its compact size, flexibility in operation, faster dynamic response, low acoustic noise, etc. An inverter has become the necessity of the day during the period of load shedding or as an interim source until the backbone supply is restored. Single phase inverters of small sizes (less than $1000 \mathrm{~W}$ ) are used in domestic installations as a source of standby electric supply. Its overall cost is less than the portable generator of the same power rating. Many conventional methods have been put forward by several researchers on mitigating harmonics in power converters. The conventional methods exhibit poor system response under line and load variations.

The Single Phase Voltage Source Inverter generates harmonic content at its output due to the non-linear characteristic of power devices. In single phase voltage source inverters, the output voltage remains more or less constant due to its low internal impedances whereas the output current varies with respect to load. Therefore the terminal voltage is determined by the inverter setup whereas the load current is determined by the load. Harmonic mitigation in an inverter is an important task for its efficient operation. Conventionally, PWM techniques are used in voltage source inverters for reducing harmonic to a certain level. Moreover, the distortions of an inverter can be reduced by using composite observers both in series and shunt of the circuitry [1]-[4]. Electromagnetic Interferences may introduce harmonics in an inverter and the attenuation of EMI improves the efficiency of inverters [5]. The low pass filter incorporated at the output of an inverter may smooth the wave pattern thereby reducing the harmonic level [6]-[8]. Soft computing techniques such as fuzzy logic controller and artificial neural networks are implemented in voltage source inverters for reducing the magnitude of harmonics below standard level [9]-[12]. The application of Walsh domain waveform analytic technique is used to express the output voltage for adjusting the switching angles in Bipolar and Unipolar Voltage schemes [13] [14]. Several optimization techniques such as Particle Swarm Optimization (PSO) and Weighted Differential Evolution based PWM are also performed to improve the inverter efficiency [15]-[17]. Inverters are also employed in renewable energy applications such as H-bridge inverter using photovoltaic optimization for increasing efficiency with minimized harmonics [18]. Bipolar notching method and reducing the dead time as well as voltage drops in the switching devices was also suggested for harmonic reduction [19] [20].

In this work, Artificial Bee Colony optimization Technique is applied to estimate the optimized values of PI-controller for reducing harmonic distortions in the single phase inverters. This controller is known as ABC-PI controller. Artificial Bee Colony Algorithm is a natural inspired optimization technique simulating the foraging behaviour of honeybees. It is a very robust and population based optimization algorithm. In ABC algorithm, the colony of artificial bees contains three groups of bees namely employed bees, onlookers and scouts. A bee going to the food source is named as employed bee. A bee waiting on the dance area for making a decision to choose a food source is called onlooker. A bee that carries out random search for discovering new sources is called scout bee [21]-[23]. Using ABC-PI algorithm, both the voltage and current harmonics are mitigated less than IEEE and IEC standards. The conventional PI controller is used for harmonic reduction in VSI, because the system behaviour is accurate due to reduction of steady-state error, reduction of overshoot, increased bandwidth, etc. In this paper, the ideas are also directly implemented digitally for single phase inverter controlled by PIC microcontroller to reduce total harmonic distortion [24]-[26].

The paper is organized as follows, in the subsequent sections; Inverter circuit analysis, Artificial Bee Colony Algorithm, MATLAB implementation of ABC-PI controller, Simulation results, Experimental setup and finally 
the conclusion.

\section{Inverter Circuit Analysis of Full-Bridge Voltage Source Inverter}

Figure 1 shows the basic block diagram representation of a full bridge voltage source inverter. In order to maintain the fundamental component at the desired level; a voltage control circuit is built with an inverter. The output of the inverter is fed to an LC filter which introduces a lag varying with the load impedance for producing oscillations. Further the LC networks minimize the THD maintaining the power factor at a specified value. The load output is then fed to a suitable controller and the controlled output is compared with the reference signal and the error signal generated is used to reduce the harmonic content of single phase inverter. In order to achieve a good dynamic behavior, the feedback control loop with fast response is required.

The inverter load voltage is defined as,

$$
V_{L}=\left\{\begin{array}{l}
V_{0}, 0<\theta<\pi \\
-V_{0}, \pi<\theta<2 \pi
\end{array}\right.
$$

Instantaneous inverter output voltage,

$$
V_{0}(t)=\sum_{n=1,3,5}^{\infty} \frac{4 V \operatorname{Sin} n \omega t}{n \pi}
$$

If the load of the inverter is purely resistive, then the load current is given by,

$$
i_{L}=\left\{\begin{array}{l}
\frac{V_{0}}{R}, 0<\theta<\pi \\
\frac{-V_{0}}{R}, \pi<\theta<2 \pi
\end{array}\right.
$$

Instantaneous inverter output current,

$$
i_{0}(t)=\sum_{n=1,3,5}^{\infty} \frac{4 V \operatorname{Sin}(n \omega t-\varphi n)}{n \pi \sqrt{R^{2}+(n \omega L)^{2}}}
$$

The power absorbed by the load is given by

$$
P_{o}=\frac{V_{o}^{2}}{R}=\frac{V_{i n}^{2}}{R}
$$

Total Harmonic Distortion (THD) is a measure of harmonic content in a signal, which is the ratio of all the harmonic components together to the rms amplitude of the fundamental. It is given by,

$$
\mathrm{THD}=\frac{V_{r m s}^{2}-V_{1}^{2}}{V_{1}}
$$

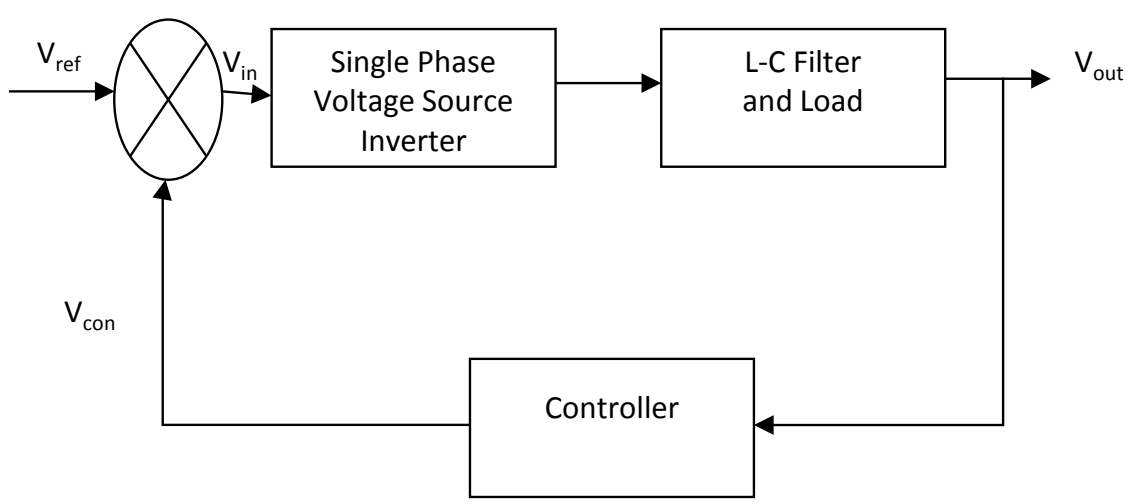

Figure 1. Block diagram representation of single phase full bridge voltage source inverter. 
In full bridge inverter, the switching frequency, $f_{s}$ must be above the audible range of $20 \mathrm{KHz}$. It is given by, switching frequency,

$$
f_{s}=\frac{1}{\frac{T}{2}+T_{\text {off }}}
$$

Supply frequency

$$
f_{s}=2 p f_{o}
$$

where, $f_{o}$ is the output frequency and " $P$ " is the pulses per half period. The source voltage and output voltages are related as,

$$
V_{s}=V_{o}-V_{o n}
$$

where, $V_{\text {on }}$ is the output voltage including on-state voltages of the switching device.

The switching scheme determines the frequency of the output ac waveform. The output voltage amplitude is controlled by varying the amplitude of the source voltage. The steady-state inverter operation can be explained by assuming two circuit modes with control variable $u €\{0,1\}$. The mathematical model for the voltage controlled single phase full bridge inverter based on bipolar voltage switching with sinusoidal pulse width modulation is presented. It is assumed that all components are ideal. The alternating voltage is produced when switches $S_{A}$ and $S_{D}$ are closed for half the switching period while $S_{B}$ and $S_{C}$ are open. In the second half-period $S_{A}$ and $S_{D}$ are open while $S_{\mathrm{B}}$ and $\mathrm{S}_{\mathrm{C}}$ are closed. The control variable " $u$ " is defined as,

$$
u(\theta)=\left\{\begin{array}{l}
0,-\alpha<\theta<\alpha \\
1, \alpha<\theta<\pi-\alpha
\end{array}\right.
$$

If switches $\mathrm{S}_{\mathrm{A}}$ and $\mathrm{S}_{\mathrm{D}}$ are on, then $u=1$. If switches $\mathrm{S}_{\mathrm{B}}$ and $\mathrm{S}_{\mathrm{C}}$ are on, then $u=0$, where $u$ is a control variable.

Topology (1): When switches $\mathrm{S}_{\mathrm{A}}$ and $\mathrm{S}_{\mathrm{D}}$ are on, then $u=1$ and the system can generate a positive half sine wave. Figure 2 shows its equivalent circuit.

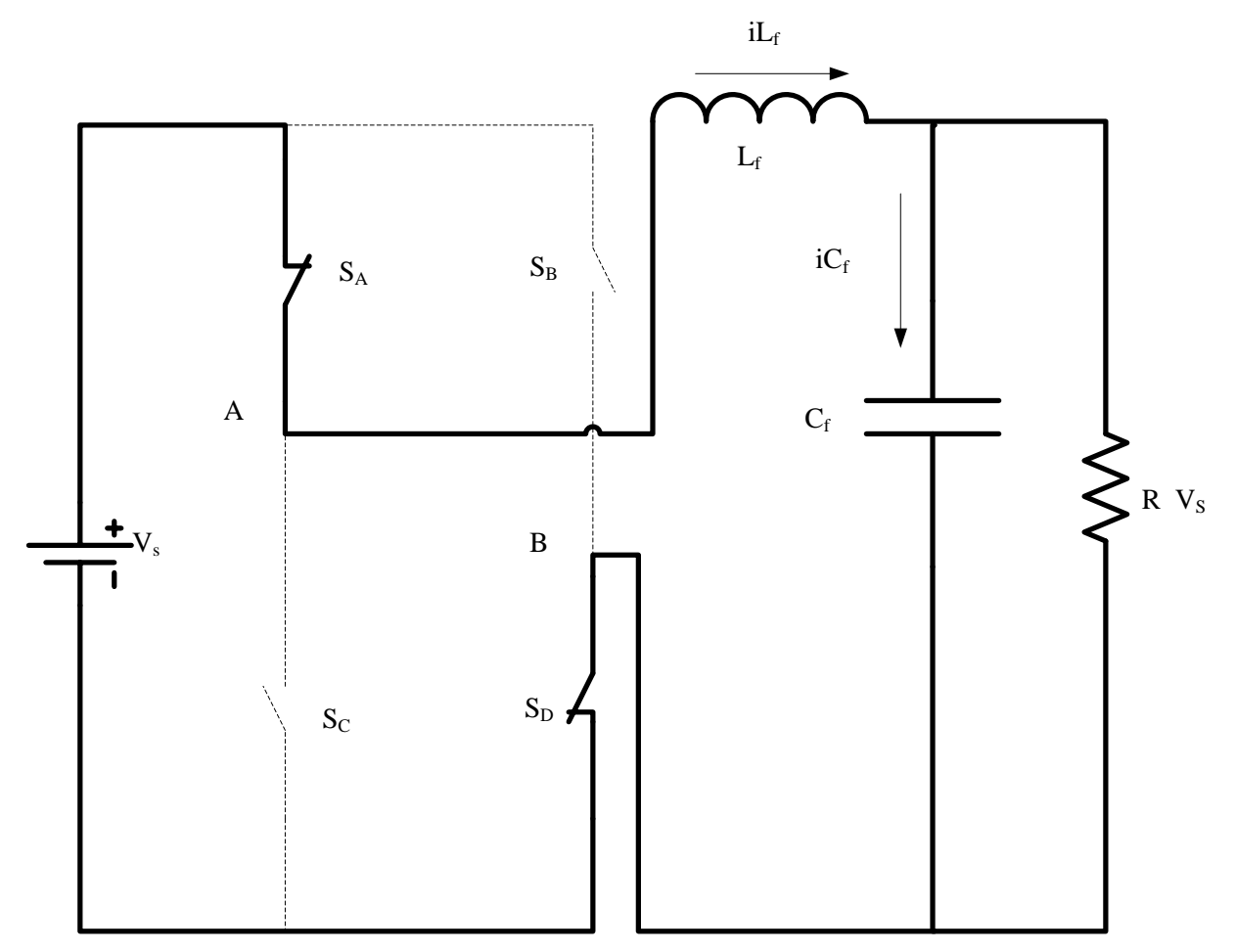

Figure 2. Circuit mode when $\mathrm{S}_{\mathrm{A}}$ and $\mathrm{S}_{\mathrm{D}}$ are $\mathrm{ON}$. 
According to the circuit topology, the state-space equation can be written as follows.

Applying KVL,

$$
\begin{gathered}
V_{i n}=L_{f} \frac{\mathrm{d} i_{L f}(t)}{\mathrm{d} t}+v_{c f}(t) \\
\frac{\mathrm{d} i_{L f}(t)}{\mathrm{d} t}=\frac{V_{i n}+v_{c f}(t)}{L_{f}}
\end{gathered}
$$

Also,

$$
\begin{gathered}
i_{L f}(t)=i_{c f}(t)+i_{R}(t) \\
i_{L f}(t)=C_{f} \frac{\mathrm{d} v_{C f}(t)}{\mathrm{d} t}+\frac{v_{c f}(t)}{R} \\
\frac{\mathrm{d} v_{C f}(t)}{\mathrm{d} t}=\frac{i_{L f}(t)}{C_{f}}-\frac{v_{c f}(t)}{R C_{f}}
\end{gathered}
$$

Topology (2): $\mathrm{S}_{\mathrm{B}}$ and $\mathrm{S}_{\mathrm{C}}$ are on, then $u=0$ and the system can generate a negative half sine wave. Figure 3 shows its equivalent circuit. According to the circuit topology, the state-space equation can be written as follows.

Applying KVL,

$$
\begin{gathered}
-V_{i n}=L_{f} \frac{\mathrm{d} i_{L f}(t)}{\mathrm{d} t}+v_{c f}(t) \\
\frac{\mathrm{d} i_{L f}(t)}{\mathrm{d} t}=\frac{-V_{i n}-v_{c f}(t)}{L_{f}}
\end{gathered}
$$

Applying KCL,

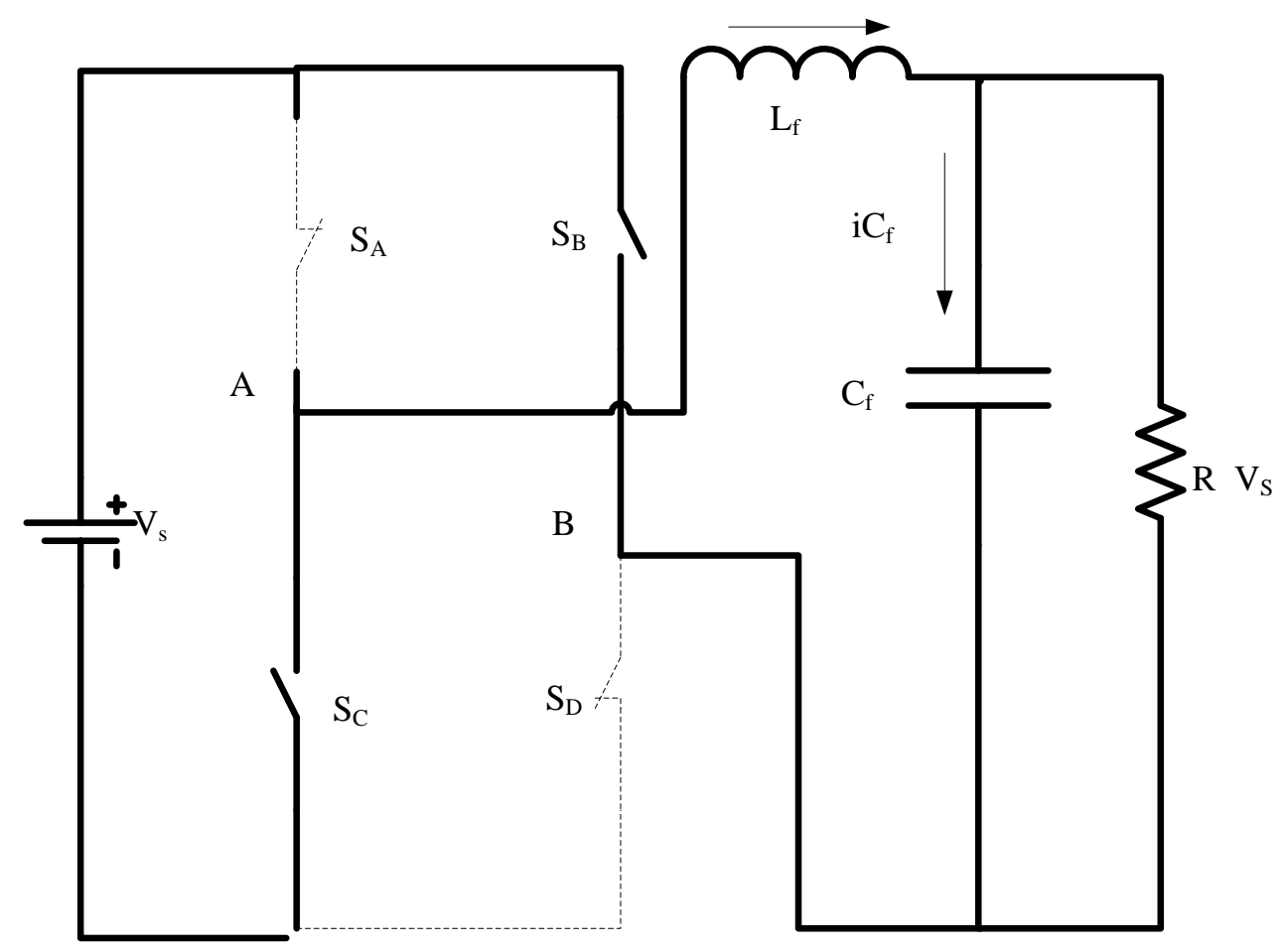

Figure 3. Circuit mode when $\mathrm{S}_{\mathrm{B}}$ and $\mathrm{S}_{\mathrm{C}}$ are $\mathrm{ON}$. 


$$
\frac{\mathrm{d} v_{C f}(t)}{\mathrm{d} t}=\frac{i_{L f}(t)}{C_{f}}-\frac{v_{c f}(t)}{R C_{f}}
$$

Equations (11) and (14) are merged with controlled variable $u \in\{0,1\}$ into following state space equation (15):

$$
\left[\begin{array}{c}
\frac{\mathrm{d} i_{L f}(t)}{\mathrm{d} t} \\
\frac{\mathrm{d} v_{C f}(t)}{\mathrm{d} t}
\end{array}\right]=\left[\begin{array}{cc}
0 & -\frac{1}{L_{f}} \\
\frac{1}{C_{f}} & -\frac{1}{R C_{f}}
\end{array}\right]\left[\begin{array}{c}
i L_{f}(t) \\
v C_{f}(t)
\end{array}\right]+\left[\begin{array}{c}
\frac{V_{i n}}{R} \\
0
\end{array}\right](2 u-1)
$$

where,

$U=$ Control variable;

$L_{f}=$ Filter inductance;

$C_{f}=$ Filter capacitance;

$R=$ Load resistance;

$V_{\text {in }}=$ DC input voltage.

\section{Passive LC Filter Design}

The LC low pass filter at the inverter terminals act as parallel resonance and blocks the harmonics into a lower level and passes almost sinusoidal output. In inverters, the LC elements are used for building up the oscillations and are called resonant elements. It should be under damped in nature such that,

$$
R_{o}^{2}<\frac{4 L}{C}
$$

Filter inductance,

$$
L_{f}=\frac{R_{0}}{\pi f_{c}}
$$

Filter capacitance,

$$
C_{f}=\frac{1}{\pi Z_{\text {ofc }}}
$$

Filter cut-off frequency,

$$
f_{c}=\frac{1}{\pi \sqrt{L C}}
$$

\section{Artificial Bee Colony (ABC) Algorithm}

Artificial Bee Colony (ABC) algorithm, proposed [23] for real parameter optimization, simulates the foraging behavior of bee colony. In this paper Harmonic reduction is a constrained optimization problem incorporated in VSI with an ABC algorithm. Artificial Bee Colony (ABC) algorithm is an optimization technique providing population based search procedure in which individuals called food positions are modified by the artificial bees with time and the bees aim is to discover the places of food sources with high nectar amount and finally the one with the highest nectar. In ABC algorithm, artificial bee fly around in a multidimensional search space and some employed and onlookers choose food source depending on the experience of themselves and their nest mates, and adjust their positions. Some scout bees fly and choose the food sources randomly without using experience. If the nectar amount of a new source is higher than that of the previous one in their memory, they memorize the new position and forget the previous one.

In ABC algorithm the colony of artificial bees contains three groups of bees: employed bees, onlookers and scouts. First half of the colony consists of the employed artificial bees and the second half includes the onlookers. For every food there is only one employed bee. In other words, the number of employed bees is equal to the 
number of food sources. The employed bee of an abandoned food source becomes a scout. The search carried out by the artificial bees can be summarized as follows:

Employed bees determine a food source within the neighborhood of the food source in their memory. Employed bees share their information with onlookers within the hive and then the onlookers select one of the food sources. Onlookers select a food source within the neighborhood of the food sources chosen by them. An employed bee of which the source has been abandoned becomes a scout and starts to search a new food source randomly.

\subsection{Pseudo-Codes for the ABC Optimization Technique}

1. Load samples of Controller parameters.

2. Initialize the population of solutions,

$X_{i}, I=1 \ldots \ldots \ldots . .$. SN (size of population).

3. Evaluate the fitness $\left(f_{i} t_{i}\right)$ of the population.

4. Set Cycle $=1$.

5. Repeat.

6. Produce new solutions for the employed bee,

$X_{\text {new }}$ by using Equation (25) and evaluate their fitness using Equation (22).

7. Apply the greedy selection process for the employed bees.

8. Calculate the probability values for the solutions

Using Equation (24).

9. Produce the new solutions for the onlookers from the solutions $X_{i}$ selected depending on probability and evaluate them.

10. Apply greedy selection process for the onlookers.

11. Determine the abandoned solution for the scout

if exists and replace it with a new randomly

Produced solution $X_{i}$ by (26).

12. Memorize the best solution so far.

13. Cycle $=$ cycle +1 Until Cycle $=$ MCN (Maximum Cycle Number).

\subsection{Objective Function}

The objective function of the VSI comprises reducing total harmonic distortion (THD), which largely depends on the controller parameters.

$$
V_{\text {in }}=V_{\text {ref }}-V_{\text {con }}
$$

where,

$V_{\text {ref }}=$ Reference d.c voltage.

$V_{\text {con }}=$ Controller d.c voltage.

Minimise THD subject to the constraint

$$
\phi_{\min } \leq \phi \leq \phi_{\max }
$$

where $\varphi$ represents $K_{p}$ and $K_{i}$.

\subsection{Fitness Function}

Fitness value $\left(f_{i} t_{i}\right)$ is calculated using iom

$$
f_{i} t_{i}=\frac{1}{1+f\left(x_{i}\right)}
$$

Here $f\left(x_{i}\right)$ is the objective function (THD) in the steady state.

\subsection{Design Procedures for $\mathrm{ABC}$ Optimization}

Figure 4 indicates the flow chart of $\mathrm{ABC}$ algorithm. In $\mathrm{ABC}$ algorithm, the position of a food source represents 


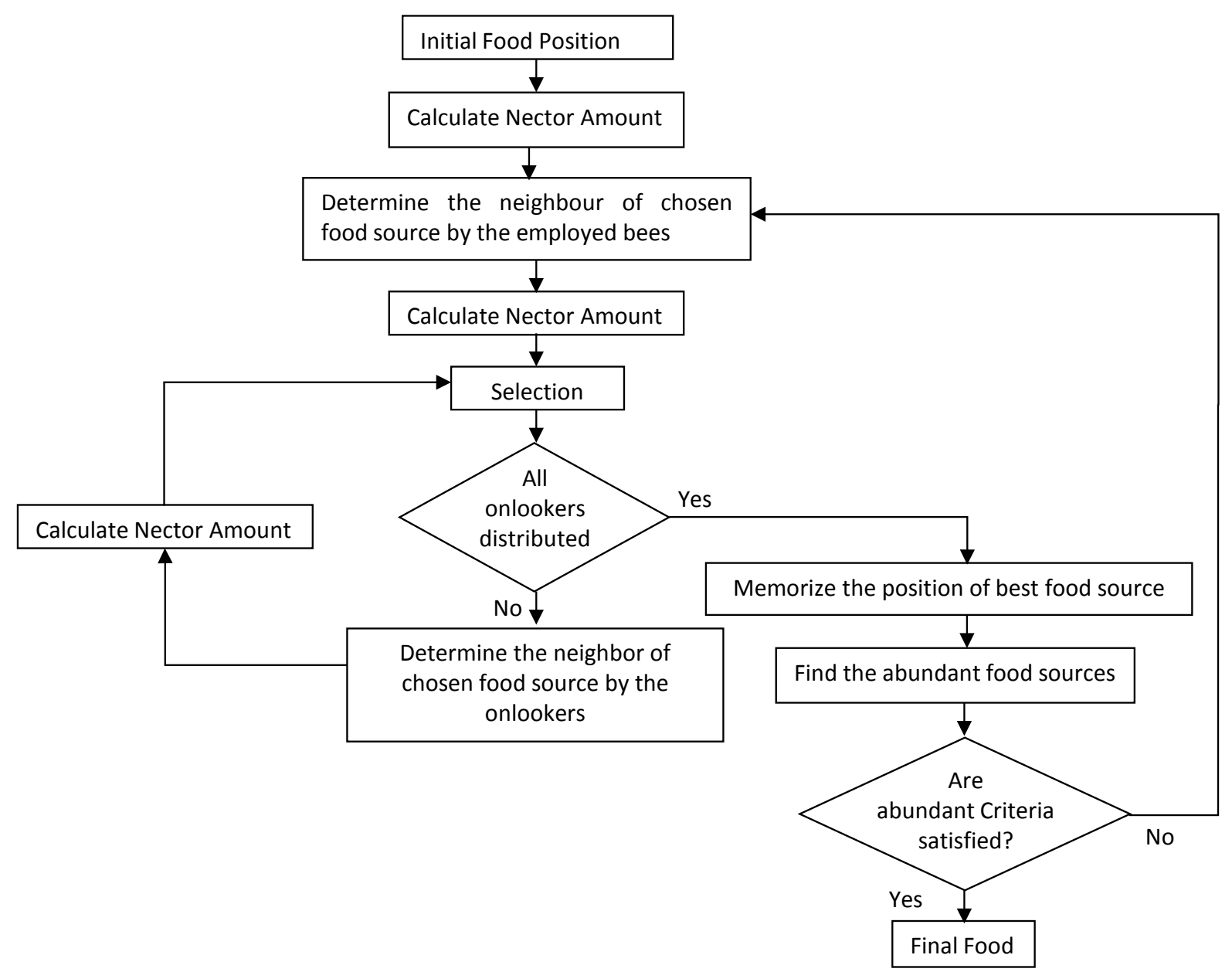

\section{Figure 4. Flow chart of ABC algorithm.}

a possible solution to the optimization problem and the nectar amount of a food source corresponds to the quality (fitness) of the associated solution. The number of the employed bees or the onlooker bees is equal to the number of solutions in the population. At the first step, the ABC generates a randomly distributed initial population $X_{i}$ of SN solutions (food source positions), where SN denotes the size of population. Each solution $i=1,2, \cdots, F S$. Where $F S$ is a D-dimensional vector and $D$ is the number of optimization parameters $K_{p} \& K_{i}$.

$$
\text { i.e. } D=\left[K_{p}, K_{i}\right]
$$

After initialization, the population of the positions (solutions) is subjected to repeated cycles, $C=1,2, \cdots, M C N$ of the search processes of the employed bees, onlooker bees and scout bees. An employed bee produces modifications on the position (solution) in the memory depending on the local information (visual information) and tests the nectar amount (fitness value) of the new source (new solution). Provided that the nectar amount of the new one is higher than that of the previous one. The bee memorizes the best food source and forgets the old one. Otherwise keeps the position of the previous one in memory. In general the position of $i^{\text {th }}$ food source is represented as:

$$
X_{i}=\left(X_{11}, X_{12}, \cdots, X_{i D}\right)
$$

After all employed bees complete the search process; they share the nectar information of the food sources and their position information with the onlooker bees on the dance area. An onlooker bee evaluates the nectar information taken from all employed bees and chooses a food source with a probability related to its nectar amount. The probability $P_{i}$ determined as, 


$$
p_{i}=\frac{f_{i} t_{i}}{\sum_{i=1}^{n} f_{i} t_{i}}
$$

where $n$ is total number of food sources. Fitness value $f_{i} t_{i}$ is calculated using (16). The onlooker finds its food source in the region of $X_{i}$ by using the following relation,

$$
X_{\text {new }}=X_{I J}+r *\left(X_{i j}-X_{k j}\right)
$$

where, $K \in(1,2,3, \cdots, F S)$ and $J \in(1,2,3, \cdots, D)$ are randomly chosen indexes, $r$ is a uniformly distributed random number in the range $[-1,1]$.

All the employed bees have completed search process, the information is shared with onlookers. The onlookers select food sources according to the above probability so that better food sources are selected. Each bee will search for a better food source for certain number of cycles (limit), and if fitness value doesn't improve then that particular bee becomes scout. In ABC algorithm, it is simulated by producing a position of scout bees randomly and replacing it with the abandoned one. If the position cannot be improved further through a predetermined of cycles, then that food source is assumed to be abandoned. The value of predetermined number of cycles is an important control parameter of the ABC algorithm, which is called "limit" for abandoned. Assume that the abandoned source is $X_{i}$ and $j \in\{1,2, \cdots, D\}$, then the scout discovers a new food source to be replaced by $X_{i}$. This operation can be expressed as

$$
X_{\text {new }}^{j}=X_{\min }^{j}+\operatorname{rand}(0.1)\left(X_{\text {new }}^{j}-X_{\text {min }}^{j}\right)
$$

\section{Simulation Results and Discussion}

The Total Harmonic Distortion of Single Phase VSI using Proportional Integral Controller with ABC Optimization is simulated by using Matlab/Simulink software. In single phase full-bridge voltage fed inverter the initial and estimated values of Proportional constant $\left(K_{p}\right)$ and Integral constant $\left(K_{i}\right)$ values are $K_{p}=19$ and $K_{i}=7.1$. In the simulation using PI controller the optimized values $K_{p}=19.862$ and $K_{i}=9$ are estimated using ABC algorithm and its THD values are computed. The switching frequency of the inverter is taken as $7.69 \mathrm{KHZ}$ [11]. The optimized controller parameters are bounded as: $\left\{0, K_{p \max }\right\},\left\{0, K_{\text {imax }}\right\}$ where, $0<K_{p} \leq 19.862$ and $0<K_{i} \leq 9$

The Specification of the 1-Phase inverter is tabulated in Table 1 it describes the parameters and values for both simulation and hardware.

The detailed closed loop simulation voltage source Inverter using Proportional Integral Controller with ABC optimization is in Figure 5. The combination of proportional and integral terms increases the speed of response

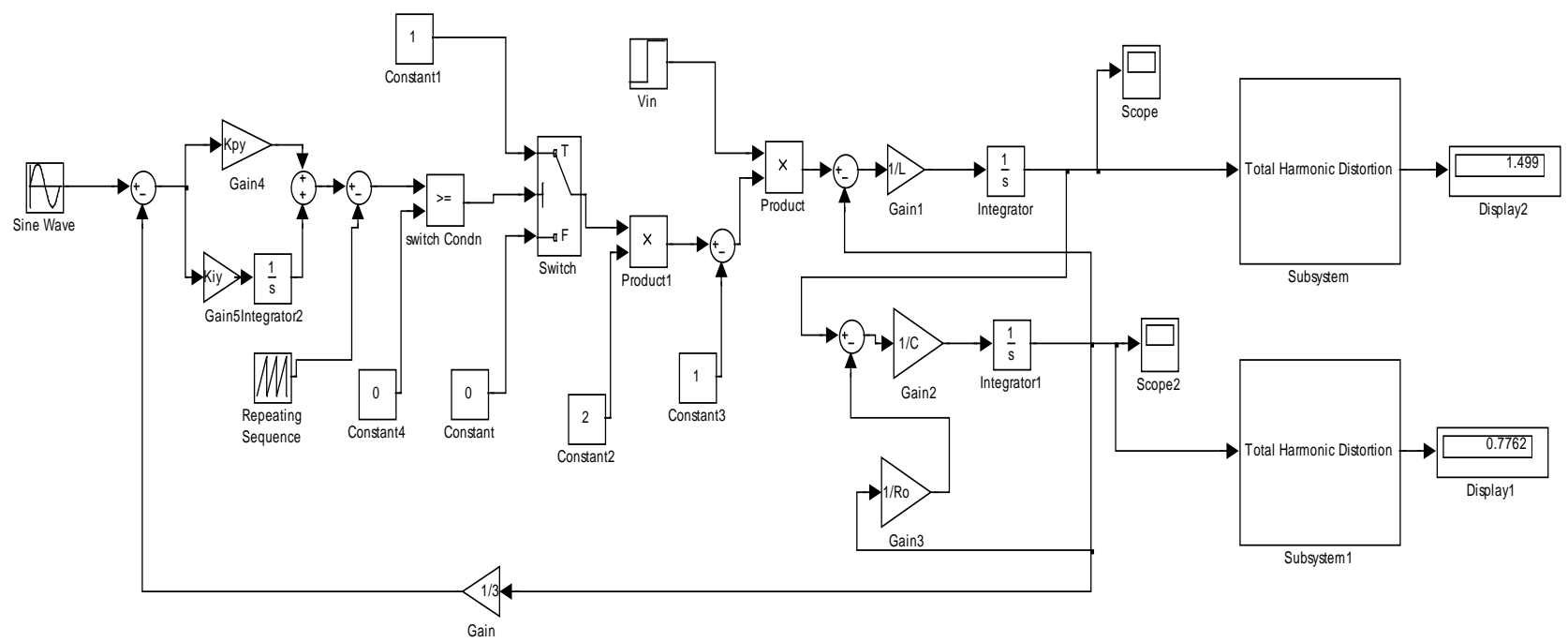

Figure 5. Closed loop simulation of a voltage source inverter using proportional integral controller with ABC optimization technique. 
Table 1. Specifications of voltage source inverter for both simulation and hardware.

\begin{tabular}{cc}
\hline Parameters & Values \\
\hline Input DC Voltage, $V_{\text {in }}$ & $15 \mathrm{~V}$ \\
Load Resistance, $R_{0}$ & $50 \Omega$ \\
Filter Inductance, $L_{f}$ & $2 \mathrm{mH}$ \\
Filter Capacitance, $C_{f}$ & $500 \mu \mathrm{F}$ \\
Reference Signal, $V_{\text {ref }}$ & $5 \mathrm{~V} \mathrm{Sine,} 50 \mathrm{~Hz}$ \\
ABC-PI Controller & $K_{p}=19.862, K_{i}=9.0$ \\
Switching Frequency, $f_{s}$ & $7.69 \mathrm{KHz}$ \\
Load Waveform & Sine wave \\
\hline
\end{tabular}

and also it eliminates the steady state error. The overall controller tuning methods include both time and frequency domain methods such as Routh-Hurwitz Criterion, Root Locus method, pole placement technique, Ziegler-Nichols tuning formula, etc. Among this techniques, the Ziegler and Nichols tuning method is used to compute PI gains of the voltage source inverter. The Output of the controller is applied to Power Inverter switches. The Percentage THD Values of voltage and current Harmonics are measured and the response Curves of voltage and current Harmonics of Single Phase Inverters are plotted in Figure 6 and Figure 7 respectively.

Figure 6 shows output voltage waveform with reduced voltage harmonics in a single phase voltage source inverter using PI controller with ABC optimization. The controller works efficiently and maintains constant magnitude of voltage with reduced distortions. Figure 7 shows output current waveform with reduced current harmonics in a Single phase voltage source inverter using PI controller with ABC optimization. It is clear that the current waveform has initial overshoots and oscillates. The controller acts effectively and minimizes the overshoots and the waveform becomes steady with reduced distortions.

\section{Experimental Setup}

Figure 8 and Figure 9 shows the block diagram representation and experimental setup of the proposed fully controlled voltage source sine wave Inverter respectively with reduced harmonics for UPS. The experimental setup consists of a step down transformer, Crystal oscillator, Peripheral Interface Controller (PIC), Driver circuit, Power device and Load. The main part of Micro-4011 trainer is PIC microcontroller, DAC, ADC, and Display. The PIC microcontroller (PIC30F4011) generates PWM wave and it is fed to a driver circuit which in used for turn on and turn off of the power device gate signals. A miniature 4 MHZ Quartz Oscillator is used as the resonator. This oscillator generates mechanical resonance of a vibrating crystal of piezoelectric material to create an electrical signal with a very precise frequency. PIC controller is used to generate Pulse Width Modulation (PWM) wave by comparing sine wave and oscillatory wave. In Figure 10 indicates the hardware output. In this Figure 10(a) represents the Voltage Waveform across Load with PIC Microcontroller using ABC-PI optimized values Figure 10(b) represents the Load Current waveform across with PIC microcontroller using ABC-PI optimized values and Figure 10(c) represents the PWM signal.

Figure 11 shows the comparative results for with and without optimization technique. From this figure it is clearly found that the controller acts very effectively and it maintains the constant output voltage and reduced current THD's for ABC optimization. The voltage harmonics depends on source stability and network impedance so that the voltage harmonics remains constant. The current harmonics are load dependent and the magnitudes get reduced using ABC optimization technique.

\section{Conclusion}

This paper demonstrates that $\mathrm{ABC}$ optimization for a single phase voltage source full bridge inverter reduces THD values better than PI controllers for harmonic mitigation. This technique also provides constant voltage and reduced current THD values. The single phase inverter using proportional integral algorithm controlled by PIC microcontroller was directly implemented using hardware setup and its total harmonic distortions were 


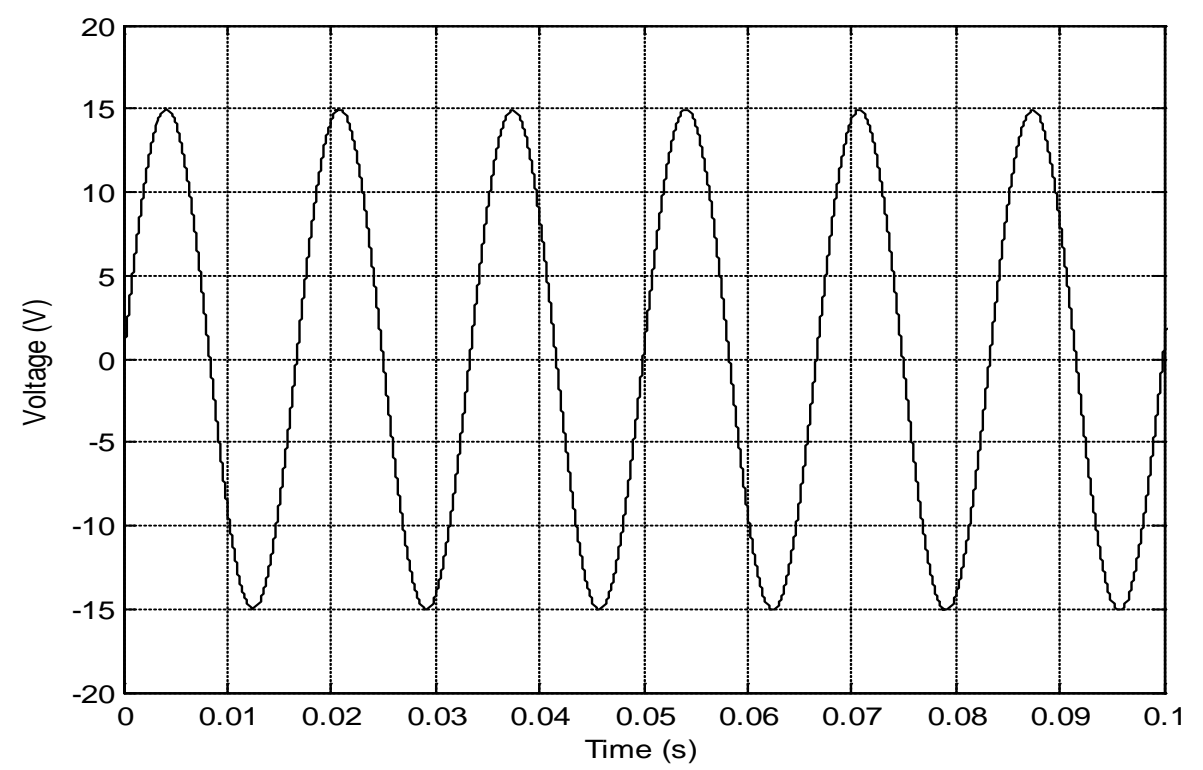

Figure 6. Variation of voltage harmonics with time using ABC-PI controller.

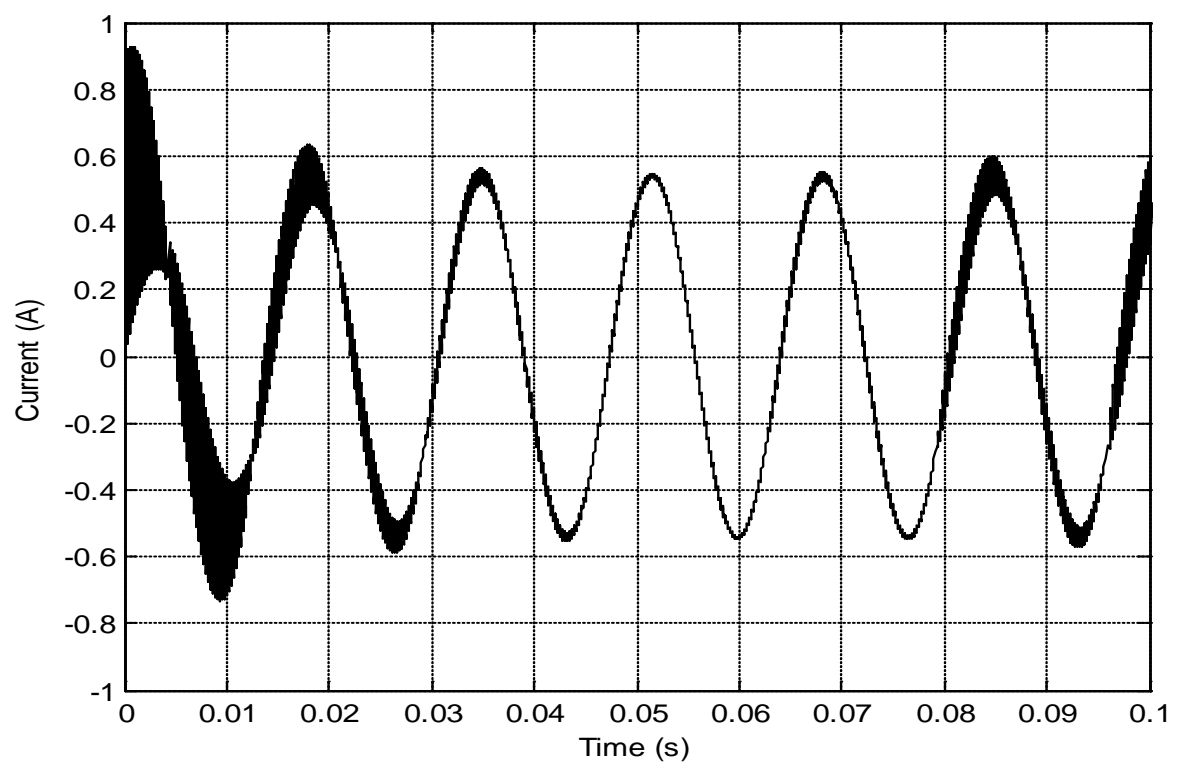

Figure 7. Variation of current harmonics with time using ABC-PI controller.

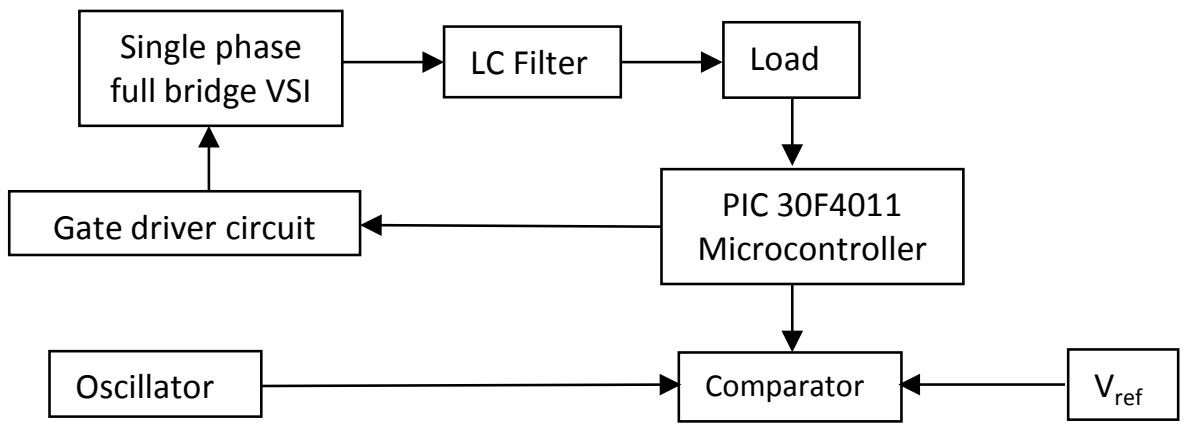

Figure 8. Block diagram of the proposed VSI for harmonic reduction. 


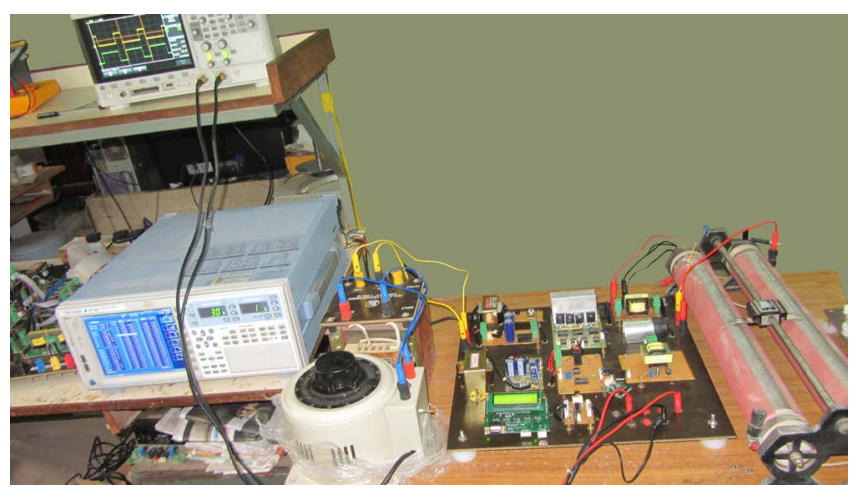

Figure 9. Hardware setup.

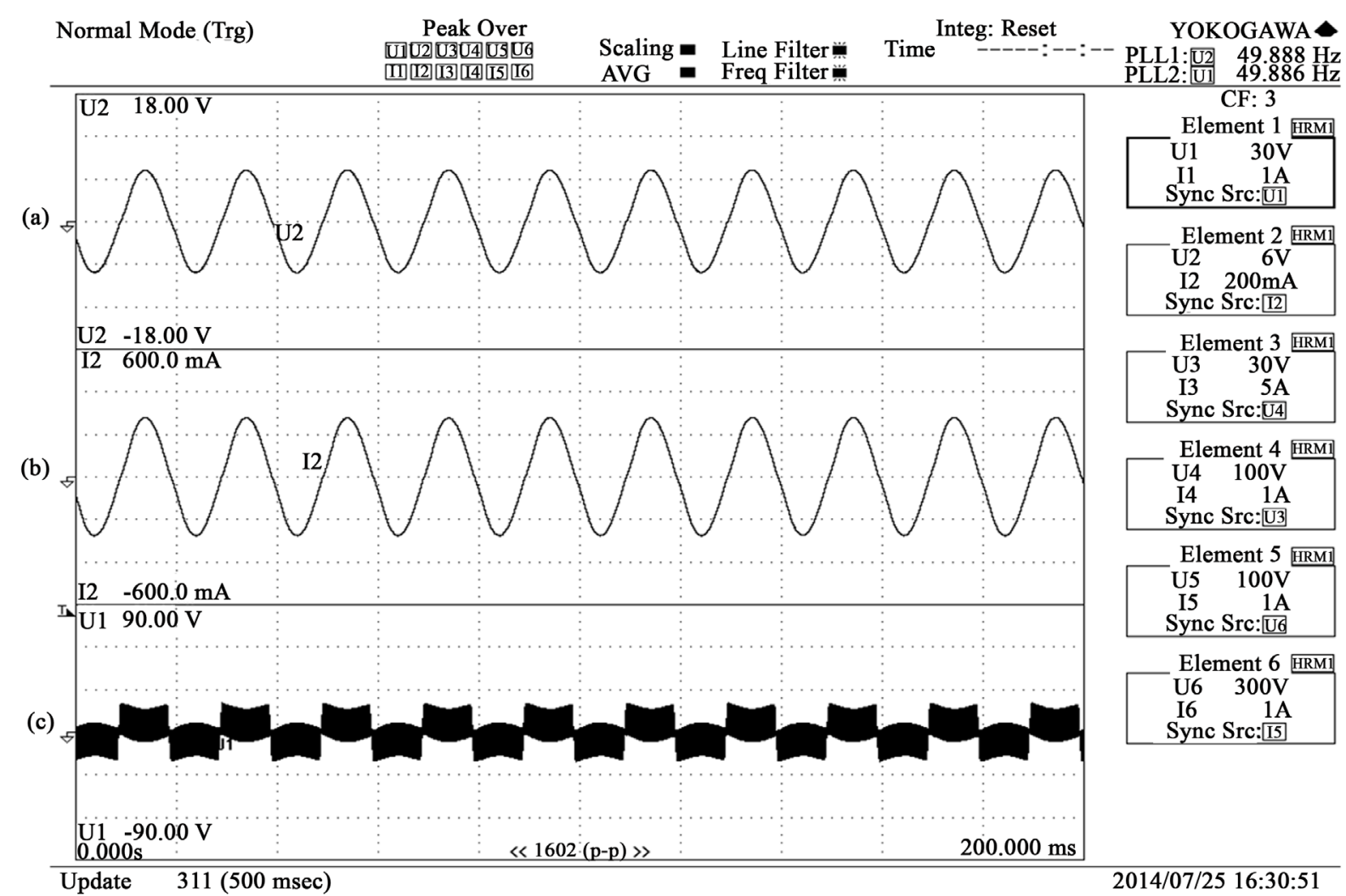

Figure 10. Hardware results. (a) Voltage waveform across load with PIC microcontroller using ABC-PI optimized values; (b) Load current waveform across with PIC microcontroller using ABC-PI optimized values; (c) PWM signal.

$$
\text { \%THDV } \quad \% \text { THDi }
$$

1.724

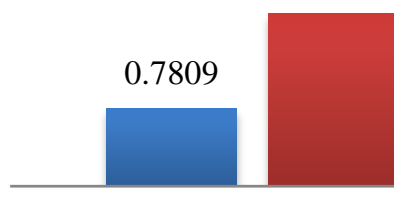

PI controller

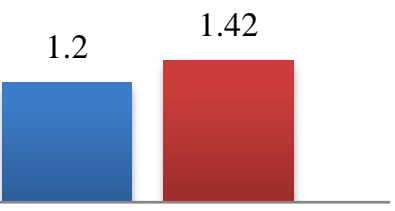

ABC-PI Optimization using PIC Microcontroller hardware setup

Figure 11. Comparison result with and without optimization. 
estimated with $\mathrm{ABC}$ optimization technique. It is observed that the optimization technique provides better reduction of current THD values compared to other non-optimization methods. This system reduces switching losses and thereby improves overall efficiency. Both software and hardware implementation provides reduced total harmonics as per IEEE and IEC standards.

\section{References}

[1] Hsieh, F.-H., Chang, P.-L., Chen, Y.-S., Wang, H.-K. and Hwang, J.-C. (2009) Fast-Scale Instability Phenomena and Chaotic Control of Voltage Control Single-Phase Full-Bridge Inverter via Varying Load Resistance. $4^{\text {th }}$ IEEE Conference on Industrial Electronics and Applications, Xi’an, 25-27 May 2009, 3422-3427. http://dx.doi.org/10.1109/iciea.2009.5138837

[2] Bhanse, J.V. and Kulkarni, S.U. (2015) New Approach for Harmonics Reduction in Inverters. International Journal of Engineering Technology, Management and Applied Sciences, 3, 187-193.

[3] Kamakshy, S. and Janakiraman, P.A. (2010) Reduction of Voltage Harmonics in Single Phase Inverters Using Composite Observers. IEEE Transactions on Power Delivery, 25, 1045-1057. http://dx.doi.org/10.1109/TPWRD.2009.2035917

[4] Kamel, A.M. and Ortmeyer, T.H. (1989) Harmonic Reduction in Single-Phase Inverter Using a Parallel Operation Technique. Fourth Annual IEEE Conference Proceedings in Applied Power Electronics Conference and Exposition, Baltimore, 13-17 March 1989, 101-108. http://dx.doi.org/10.1109/APEC.1989.36957

[5] Kim, H. and Erickson, R. (2014) Design of EMI Filters Having Low Harmonic Distortion in High-Power-Factor Converters. IEEE Transactions on Power Electronics, 29, 3403-3413. http://dx.doi.org/10.1109/TPEL.2013.2281174

[6] Kim, H. and Sul, S.-K. (2011) A Novel Filter Design for Output LC Filter of PWM Inverters. Journal of Power Electronics, 11, 4-8. http://dx.doi.org/10.6113/jpe.2011.11.1.074

[7] Reddy, B.G. and Maheswari, L. (2016) Harmonics Reduction of a Single Phase Half Bridge Inverter. International Journal of Science, Engineering and Advanced Technology, 4, 10-13.

[8] Gaurav, T., Pankaj, G., Nilesh, W. and Nitin, P. (2013) A Review on Ripple Current Reduction Technique with Active Power Filter. International Journal of Engineering and Computer Science, 2, 1457-1464.

[9] Anooja, C.L. and Leena, N. (2013) Single Phase Shunt Active Filter with Fuzzy Controller for Harmonic Mitigation. International Journal of Scientific \& Engineering Research, 4, 445-451.

[10] Jain, A. and Jain, S. (2015) Harmonic Reduction Technique in Inverter with Different Techniques Including Fuzzy Logic Controller. International Journal of Science and Research, 4, 1819-1823.

[11] Balasubramanian, R., Parkavi Kathirvelu, K., Sathishkumar, K., Amirtharajan, R. and Palani, S. (2014) Fuzzy Based Single Phase Double-Tuned Current Source Inverter with Reduced Harmonics for Microgrid. Journal of Applied Sciences, 14, 2098-2108. http://dx.doi.org/10.3923/jas.2014.2098.2108

[12] Mazumder, S., Dutta, S. and Samanta, A. (2015) Design of Inverters with Harmonics Reduction Technique Using Artificial Neural Network. International Journal of Innovation Science, Engineering and Technology, 2, 194-199.

[13] Liang, T.-J., O’Connell, R.M. and Hoft, R.G. (1997) Inverter Harmonic Reduction Using Walsh Function Harmonic Elimination Method. IEEE Transactions on Power Electronics, 12, 971-982. http://dx.doi.org/10.1109/63.641495

[14] Rode, S.V. and Ladhake, S.A. (2011) A Revision Technique for Reduction of Harmonic Distortion. International Journal of Electrical and Power Engineering, 5, 62-64. http://dx.doi.org/10.3923/ijepe.2011.62.64

[15] Shindo, T., Kurihara, T., Taguchi, H. and Jinno, K. (2011) Particle Swarm Optimization for Single Phase PWM Inverters. IEEE Congress on Evolutionary Computation, New Orleans, 5-8 June 2011, 2501-2505. http://dx.doi.org/10.1109/cec.2011.5949928

[16] Shindo, T. and Jinno, K. (2014) Switching Angles Optimization of Single Phase PWM DC-AC Inverter by Particle Swarm Optimization. Journal of Advanced Computation Intelligence and Intelligent Informatics, 18, 435-442. http://dx.doi.org/10.20965/jaciii.2014.p0435

[17] Yahia, H., Liouane, N. and Dhifaoui, R. (2010) Weighted Differential Evolution Based PWM Optimization for Single Phase Voltage Source Inverter. International Review of Electrical Engineering, 9, 125-130.

[18] Narish Kumar, V., Lavanya, G., Kumar, P., Abuzaid, S. and Ramkumar, B. (2014) Harmonic Reduction Technique in Solar Inverters. Interntional Journal of Engineering Science Research, 4, 241-247.

[19] Tutkun, N. (2011) Improved Power Quality in a Single Phase PWM Inverter Voltage with Bipolar Notches through the Hybrid Algorithms. International Journal on Expert Systems with Applications, 37, 5611-5620.

[20] Oliva, A., Chiacchiarini, H., Aymonino, A. and Mandolesi, P. (2005) Reduction of Total Harmonic Distortion in Power Inverters. Latin American Applied Research, 35, 89-93. 
[21] Ali Ebrahim, E. (2015) Power-Quality Enhancer Using an Artificial Bee Colony-Based Optimal-Controlled Shunt Active-Power Filter. WSEAS Transactions on Systems, 14, 91-101.

[22] Dervis, K. and Akay, B. (2009) A Comparative Study of Artificial Bee Colony Algorithm. Applied Mathematics and Computation, 214, 108-132. http://dx.doi.org/10.1016/j.amc.2009.03.090

[23] Dervis, K. and Basturk, B. (2007) A Powerful and Efficient Algorithm for Numerical Function Optimization: Artificial Bee Colony (ABC) Algorithm. Journal of Global Optimization, 39, 459-471. http://dx.doi.org/10.1007/s10898-007-9149-x

[24] Patel, H. and Vaghela, D. (2015) Design and Development of Online UPS Using PIC Microcontroller. International Research Journal of Engineering and Technology, 2, 429-431.

[25] Microchip Technology Incorporated (2005) High Performance Digital Signal Controllers. DsPIC30F4011/4012 Data sheet, pp. 1-4.

[26] Milan, V. (2008) PIC Microcontrollers. Mikroelektronika.

\section{Submit or recommend next manuscript to SCIRP and we will provide best service for you:}

Accepting pre-submission inquiries through Email, Facebook, Linkedin, Twitter, etc A wide selection of journals (inclusive of 9 subjects, more than 200 journals)

Providing a 24-hour high-quality service

User-friendly online submission system

Fair and swift peer-review system

Efficient typesetting and proofreading procedure

Display of the result of downloads and visits, as well as the number of cited articles

Maximum dissemination of your research work

Submit your manuscript at: http://papersubmission.scirp.org/ 